\title{
Capsules containing entomopathogenic nematodes as a Trojan horse approach to control the western corn rootworm
}

\author{
Ivan Hiltpold • Bruce E. Hibbard • \\ B. Wade French - Ted C. J. Turlings
}

Received: 27 January 2012 / Accepted: 9 April 2012 /Published online: 5 May 2012

(C) Springer Science+Business Media B.V. 2012

\begin{abstract}
Aims The use of entomopathogenic nematodes in the biological control of soil insect pests is hampered by the costly and inadequate application techniques. As a possible solution we evaluated a nematode encapsulation approach that offers effective application and may possibly attract the pest by adding attractants to the capsule shell.

Methods Heterorhabditis bacteriophora nematodes, which show high virulence against the maize root pest Diabrotica virgifera virgifera, were encapsulated in a polysaccharide shell derived from the algae Laminaria ssp. Shells of varying thickness and composition were evaluated.
\end{abstract}

Responsible Editor: Hans Lambers.

I. Hiltpold · T. C. J. Turlings $(\bowtie)$

Fundamental and Applied Research in Chemical

Ecology (FARCE) laboratory, University of Neuchâtel,

Neuchâtel, Switzerland

e-mail: ted.turlings@unine.ch

I. Hiltpold

205 Curtis Hall, University of Missouri,

Columbia, MO 65211-7020, USA

B. E. Hibbard

USDA-ARS, 205 Curtis Hall, University of Missouri,

Columbia, MO 65211-7020, USA

B. W. French

USDA-ARS,

2923 Medary Avenue,

Brookings, SD 57006, USA
Results Nematodes readily survived the encapsulation process and were able, varying with shell thickness and temperature, to break through the shell and subsequently infect hosts. The added attractants and feeding stimulants to the shell attracted the pest larvae as much as maize roots. In field trials, encapsulated $H$. bacteriophora nematodes were more effective in controlling $D$. $v$ virgifera than those sprayed in water over the soil surface, but in these trials the addition of stimulants did not increase the control efficiency.

Conclusions The study demonstrates that nematodes can be successfully applied in capsules in the field. Further improvements are needed to make the capsules a cost effective alternative to conventional field application of nematodes.

Keywords Entomopathogenic nematodes . Heterorhabditis bacteriophora $\cdot$ Heterorabditidae . Western corn rootworm · Diabrotica virgifera virgifera . Chrysomelidae Application technique .

Biological control - Belowground pest management . Plant protection

\section{Introduction}

Entomopathogenic nematodes (EPN) of the genera Steinernema and Heterorhabditis are obligate parasites of insects. After entering their host, these soildwelling microorganisms release their symbiotic 
bacteria, of the genera Xenorhabdus and Photorhabdus respectively, which multiply and kill the insect by septicemia. The nematodes then feed on the bacteria and produce several new generations inside the cadaver (Burnell and Stock 2000). When nutrients are consumed and space is exhausted, a new generation of infective juveniles leaves the cadaver in search of new insect hosts (Kaya and Gaugler 1993). These unique traits make EPN important candidates for biological control of various economic pests (Grewal et al. 2005). To target belowground (e.g. Ansari et al. 2009; Batalla-Carrera et al. 2010; Shapiro-Ilan et al. 2010b), as well as aboveground insect pests (e.g. Mbata and Shapiro-Ilan 2010; Batalla-Carrera et al. 2010; Shapiro-Ilan et al. 2010a), commercially available EPN have to be correctly applied to ensure that they reach and infect their target pest (Shapiro-Ilan et al. 2006). Their high sensitivity to UV radiation (Gaugler and Boush 1978) limits their foliar application and is also a critical factor in application of EPN to soil (Shapiro-Ilan et al. 2006). In addition, abiotic factors such as moisture, temperature or soil $\mathrm{pH}$ and texture may impact EPN application above- as well as belowground (Shapiro-Ilan et al. 2006).

Shapiro-Ilan et al. (2006) reviewed the wide range of EPN application techniques and technologies. Briefly, EPN can be sprayed over fields or orchards via irrigation systems or aerial application, which exposes them to potentially lethal water pressures and drought stress. After application, nematodes face the risk of desiccation and/or exposure to high UV radiation levels. It is therefore widely advised to apply EPN to soil in the evening or early morning when UV radiation is low. To further improve EPN survival, several formulations have been developed to ensure a satisfactory protection of the nematodes. These formulations, based on the addition of anti-desiccants, aim to keep moisture high. An alternate approach is the application of insect cadavers infected with EPN. To avoid rupture of the cadaver and facilitate their storage, handling and application, EPN infected insects can be coated with a protective formulation (Shapiro-Ilan et al. 2001) or hard-bodied insect hosts such as Tenebrio molitor L. can be applied (Shapiro-Ilan et al. 2003).

Under certain circumstances, EPN have proven their high potential to control insect pests but because of constrains of application described above they are barely used in large-scale cropping systems. The western corn rootworm Diabrotica virgifera virgifera LeConte (Coleoptera: Chrysomelidae, WCR) is among the pests targeted to be controlled by EPN. This major maize pest in the American Corn Belt was first discovered in Eastern Europe in 1992 after being accidentally introduced. Since then, it has rapidly spread and has become a serious problem, mainly in the Baltic region (Gray et al. 2009). The larval stage of this beetle can cause significant damage to the maize root, leading to reduction of plant growth, deficiencies in nutrient and water uptake, plant lodging, increased susceptibility to water stress and reduced grain yield (Apple and Patel 1963; Chiang et al. 1980; Godfrey et al. 1993; Gray and Steffey 1998; Hou et al. 1997; Riedell et al. 1992; Riedell and Kim 1990; UriasLopez et al. 2000). This combination of factors plus control measures that are being employed to avoid them result in losses estimated at 2 billion US\$ per year in the USA (Mitchell 2011). In Europe, future maximum annual costs are estimated at $€ 1.5$ billion (Wesseler and Fall 2010). Because this insect has such a negative impact on maize agriculture, European growers have begun to apply granular soil insecticides or to use insecticidecoated seeds. In some cases, this has had tremendous negative effects on non-target insects, including bees (Girolami et al. 2009; Marzaro et al. 2011). As an alternate solution, crop rotation has so far been quite successful in controlling this chrysomelid pest in certain parts of Europe, but this strategy is not an option for other regions (Levine et al. 2002; Gray et al. 2009).

Based on a literature review of the natural enemies of WCR, Kuhlmann and van der Brugt (1998) concluded that EPN have great potential to control WCR in European maize fields. So far, control levels have been highly variable. Understanding the reasons for this variability by studying the factors that determine the foraging and infection success of EPN is expected to reveal how we can optimally exploit their control potential. Rasmann et al. (2005) found that roots of European maize varieties damaged by WCR larvae emit the sesquiterpene $(E)$ - $\beta$-caryophyllene $(\mathrm{E} \beta \mathrm{C})$, an attractant for the EPN Heterorhabditis megidis Poinar (Rhabditida: Heterorhabditidae). American maize varieties have lost the ability to produce $\mathrm{E} \beta \mathrm{C}$ (Köllner et al. 2008). Using a transgenic approach Degenhardt et al. (2009) restored the maize E $\beta C$ emission in an American maize line and demonstrated that it is indeed needed to ensure consistent levels of control of the WCR larvae with EPN.

However, root-produced volatiles not only provide maize with an efficient indirect root defense (Hiltpold 
and Turlings 2008; Hiltpold et al. 2010c), they may also be exploited by WCR larvae to locate suitable maize roots in soil. Besides inducible volatiles, roots continuously and passively emit compounds like $\mathrm{CO}_{2}$, sugars and/or lipids in soil (Johnson and Gregory 2006), which also can serve as foraging cues for soil organisms. Strnad and Bergman (1986) were the first to report that WCR larvae are attracted to $\mathrm{CO}_{2}$ and this was further confirmed in experiments that used $\mathrm{CO}_{2}$ to disrupt host location by WCR larvae (Bernklau et al. 2004). Besides this general plant secondary metabolite, maize roots also emit specific sugars and fatty acids that attract WCR larvae and/or stimulate their feeding behavior (Bernklau and Bjostad 2008; Bjostad and Hibbard 1992; Hibbard et al. 1994). Moreover, WCR larvae were found to be preferentially attracted to already damaged root systems on which they perform better and they use $\mathrm{E} \beta \mathrm{C}$ as a signal find such roots (Robert et al. 2012b).

We exploited the identification of several of these stimulatory compounds to develop EPN-filled capsules that can be employed to facilitate EPN application in the field and that can disrupt larval foraging. In the current study, we assessed the impact of the encapsulation process on the infectivity of the EPN and we tested how incorporation of different blends of attractants and feeding stimulants in the capsules outer shell affected WCR attraction under laboratory and field conditions.

\section{Materials and methods}

Nematodes, insects and plants

The entomopathogenic nematode Heterorhabditis bacteriophora Poinar was obtained from LANDIReba AG (Basel, Switzerland). EPN were formulated in water and stored at $10^{\circ} \mathrm{C}$ prior to experiments. Over time, four different batches of EPN were used to perform the experiments.

Non-diapausing eggs of WCR were obtained from the USDA-ARS North Central Agricultural Research Laboratory (Brookings, South Dakota, USA) for laboratory studies. Ready to hatch eggs were deposited on germinated corn kernels from the variety Ronaldinio (LANDI-Reba AG, Basel, Switzerland) and stored in the dark at $20^{\circ} \mathrm{C}$. The seedlings were regularly sprayed with water to keep them moist and newly germinated seedlings were added when needed.
Maize seedlings (Zea mays L. variety Delprim) used for the experiments were grown in climate chambers $\left(30^{\circ} \mathrm{C}, 8: 16 \mathrm{~h}\right.$ dark:light photoperiod, CLF Plant Climatics, Percival, Germany). Kernels were sown in plastic tubes (4 $\mathrm{cm}$ diameter, $11 \mathrm{~cm}$ depth) filled with standard potting soil (Ricoter Aussaaterde, Aarberg, Switzerland) and watered every day. In total, 15 plants were used in the experiments. After 10 days, the seedlings were transplanted in the experimental setup to assess WCR larval choices for different treatments (see "WCR larval behavior" section for details).

\section{Encapsulation of EPN}

Encapsulation of EPN in an alginate shell was based on reverse spherification principles. Briefly, a solution with a high concentration of $\mathrm{Ca}^{2+}$ ions is dripped in an alginate bath. Alginates, polysaccharides extracted from the brown algae Laminaria spp., polymerize in contact with $\mathrm{Ca}^{2+}$. This process results in the formation of a spherical shell that surrounds a liquid core.

The liquid solution, eventually forming the liquid core of the capsule, was obtained by mixing demineralized water with calcium gluconolactate (Gluco, Texturas by Albert \& Ferran Adrià, Solegraells, Barcelona, Spain). Adding of xanthan gum, a polysaccharide resulting from bacterial fermentation (Xanthan, Texturas by Albert \& Ferran Adrià, Solegraells, Barcelona, Spain) increased the viscosity of the solution to help in the formation of spheres instead of tearshaped capsules. A few drops of food dye were added in order to distinguish the solution during the formation of the capsules (see below for details). The final solution was homogenized with an electric immersion blender. Remaining air bubbles in the solution were vacuumed out and the solution was stored at $-20^{\circ} \mathrm{C}$. Concentrations of the different chemical compounds are given in the Table 1.

The liquid solution that formed the outer polymeric shell was obtained by mixing sodium alginate (Algin, Texturas by Albert \& Ferran Adrià, Solegraells, Barcelona, Spain) with demineralized water. The final solution was homogenized with an electric immersion blender. Remaining air bubbles in the solution were vacuumed out and the solution was store at $-20^{\circ} \mathrm{C}$. Concentrations of the different chemical compounds are given in the Table 1. 
Table 1 Formulations of the two solutions used for the formation of the Algcapsule. The quantities are given for $100 \mathrm{ml}$ of solution. The alginate is used as alimentation add-ons (E400 to E405). Xanthane, a polyoside, is used to adjust the viscosity of the $\mathrm{Ca}^{2+}$ solution. This compound is extracted from the bacterium Xanthomonas campestris. It commonly used in food industry under the code E415

\begin{tabular}{|c|c|c|c|}
\hline Compound & $\begin{array}{l}\text { Quantity } \\
{[\mathrm{g}]}\end{array}$ & Why? & \\
\hline $\begin{array}{l}\text { Alginate }((2 \mathrm{R}, 3 \mathrm{~S}, 4 \mathrm{R}, 5 \mathrm{R}, 6 \mathrm{~S})-6-[(2 \mathrm{R}, 3 \mathrm{R}, 4 \mathrm{R}, 5 \mathrm{R}, 6 \mathrm{~S})- \\
\text { 2-carboxy-4, 5-dihydroxy-6-methoxyoxan-3-yl]oxy-4, } \\
\text { 5-dihydroxy-3-methoxyoxane-2-carboxylic acid, } \\
\text { CAS 9005-32-7) }\end{array}$ & 0.5 & $\begin{array}{l}\text { Using } \mathrm{Ca}^{2+} \text { ions as binder, alginate polymerizes } \\
\text { around a droplet of } \mathrm{Ca}++ \text { water solution }\end{array}$ & SHELL \\
\hline Calcium $\left(\mathrm{Ca}^{2+}\right.$, CAS 7440-70-2) & 2.0 & $\begin{array}{l}\text { Calcium is binding alginate molecules in a polymeric } \\
\text { shell around the droplet. It is important to have enough } \\
\text { of it in order to initiate a good polymerization but } \\
\text { excess would lead to an unviable environment for } \\
\text { nematodes. }\end{array}$ & $\begin{array}{l}\text { Fluid inner } \\
\text { core of the } \\
\text { capsule }\end{array}$ \\
\hline Xanthane (CAS 11138-66-2) & 0.4 & $\begin{array}{l}\text { Xanthane is thickening the } \mathrm{Ca}^{2+} \text { solution in order to } \\
\text { allow the formation of "sphere". If the solution is too } \\
\text { fluid, it would result in the format ion of filaments. }\end{array}$ & \\
\hline Food dye & $\begin{array}{l}\text { depends } \\
\text { on the } \\
\text { dye }\end{array}$ & $\begin{array}{l}\text { A dye helps to contrast the two solutions. If no dye is } \\
\text { added, once the droplet is in the alginate solution, } \\
\text { there is no way to distinguish them. }\end{array}$ & \\
\hline
\end{tabular}

A few minutes before encapsulation, EPN were poured into the calcium gluconolactate solution. The liquid was gently shaken to homogenize nematode distribution. Using a $1 \mathrm{ml}$ syringe (Henke Sass Wolf $\mathrm{GmbH}$, Tuttlingen, Germany), the solution was dripped on the surface of the alginate bath in drops of approximately $50 \mu$ l. The numbers of nematodes that were encapsulated depended on the experiment for which the capsules were made. After the formation of the sphere, the shell of the capsules was allowed to polymerize for $5 \mathrm{~min}, 7 \mathrm{~min}, 10 \mathrm{~min}, 15 \mathrm{~min}$ or $20 \mathrm{~min}$. These different polymerization times determined the thickness of the shell ranging from thin $(5 \mathrm{~min}$ in the alginate bath) to thick (20 $\mathrm{min}$ in the alginate bath). Capsules were removed from the alginate bath with a fine mesh strainer, rinsed with water and stored at $7^{\circ} \mathrm{C}$ in $15 \mathrm{ml}$ Falcon tubes (VWR, Dietikon, Switzerland) filled with water.

EPN breakthrough from the capsules

Nematodes in capsules of increasing shell thickness (as described in previous section) were used to test the effects of temperature and shell polymerization times (shell thickness) on EPN breakthrough. Each capsule contained approximately 130 nematodes. These capsules were then stored individually in $15 \mathrm{ml}$ of water in Falcon tubes (15 ml, VWR, Dietikon, Switzerland), either in the fridge $\left(7^{\circ} \mathrm{C}\right)$ or at room temperature $\left(25^{\circ} \mathrm{C}\right)$.
Every day, an aliquot of $1 \mathrm{ml}$ of water was sampled from the bottom of each tube and the number of escaped nematodes was recorded.

Ability of the encapsulated nematodes to kill insect host

In order to assess the ability of the encapsulated EPN to kill an insect host after exiting the capsules, $50 \mathrm{ml}$ Falcon tubes (VWR, Dietikon, Switzerland) were filled with $60 \%$ moist potting soil (Ricoter Aussaaterde, Aarberg, Switzerland). Larvae of Galleria mellonella L. (Lepidoptera: Pyralidae), employed as insect baits, were placed in plastic specimen tubes $(8 \mathrm{~mm}$ diameter, $32 \mathrm{~mm}$ height, $1 \mathrm{ml}$, Kartell, VWR, Dietikon, Switzerland) in which we had drilled thirteen $2.5 \mathrm{~mm}$ diameter holes. Falcon tubes $(50 \mathrm{ml})$ were individually prepared with such a Galleria bait placed at the edge of the tube (so that they were visible from the outside), $4 \mathrm{~cm}$ below the soil surface.

Escaping from the capsule may cost energy and thus the thickness of the shell might negatively impact the infectiousness of the EPN. To test this potential negative influence of the shell thickness, H. bacteriophora were encapsulated in 10 capsules of each polymerization period (approximately 130 EPN per capsule, for details see the "Encapsulation of EPN" section). Capsules were individually placed on top of the soil in a Falcon tube and 
covered with $1 \mathrm{~cm}$ of additional soil. As a control, 10 additional Falcon tubes received $G$. mellonella only.

In order to allow gas exchange, the Falcon tubes were only half closed and stored in the dark at room temperature. G. mellonella infection was visually evaluated each day following the beginning of the experiment. The number of days needed for the $G$. mellonella to turn red, a sign of successful EPN infection (Forst and Clarke 2002), was recorded for each tube. In the control tubes, the survival of $G$. mellonella was assessed 7 days after the experiment had started.

\section{Attraction of WCR larvae}

Whether WCR larvae can be attracted towards the capsules by adding known feeding stimulants to the capsule shell was first assessed in Petri dish assays. Three alginate formulations were tested, (i) a formulation made of 95:5 demineralized water:corn root juice mixed with alginate, (ii) a formulation containing alginate and a synthetic blend of linoleic acid, oleic acid, stearic acid, glucose, fructose, sucrose and MBOA (for concentrations and references see Table 2) and (iii) a formulation with alginate only as a control. EPN-free capsules (around $0.5 \mathrm{~cm}$ diameter) were produced allowing a $10 \mathrm{~min}$ polymerization period. The root juice was obtained by grinding maize roots in liquid nitrogen, filtering the resulting powder, and collecting the remaining liquid.
For each test, 10 Petri dishes $(10 \mathrm{~cm}$ diameter, $1.5 \mathrm{~cm}$ deep) were subdivided in three equal parts. A capsule of each formulation was placed in each third, $3 \mathrm{~mm}$ from the dish edge. The Petri dish was immediately filled with $60 \%$ moist potting soil (Ricoter Aussaaterde, Aarberg, Switzerland). Using a paintbrush, 6 second instar WCR larvae were carefully deposited on top of the soil in the center of the Petri dish. The dishes were then closed and stored in dark in an incubator $\left(25^{\circ} \mathrm{C}, 90 \%\right.$ humidity). After $4 \mathrm{~h}$, a core (1.5 cm diameter) of soil surrounding and containing each capsule was sampled and the number of WCR larvae present in each sample was recorded.

In order to get a more realistic assessment of the attraction of WCR larvae towards capsules, a second experiment was conducted in soil-filled plastic boxes $(38.5 \times 25.8 \times 17 \mathrm{~cm}$ int. dimensions, stacking container RAKO, Georg Utz AG, Switzerland). The racks were made of a wood frame $(25 \times 16 \times 2.8 \mathrm{~cm}$, pine wood, Migros, Switzerland) and a plastic mesh $(0.5 \times 0.5 \mathrm{~cm}$, Migros, Switzerland) through which the WCR larvae could freely move. The top of each rack was left open allowing the device to be filled up with $60 \%$ moist potting soil (Ricoter Aussaaterde, Aarberg, Switzerland). In each box, five racks were arranged at equal distance from each other. From left to right, the racks contained (1) soil with one maize plant, (2) soil only, (3) soil with 30 WCR larvae, (4) soil only and (5) soil with capsules. The contents of racks (1) and (5) varied,

Table 2 Formulation of the synthetic blend of attractants for the WCR larvae. This list is based on information from the indicated literature. The chemicals were mixed with alginate (Table 1) in a homogeneous solution

\begin{tabular}{|c|c|c|c|c|}
\hline $\begin{array}{l}\text { Class of } \\
\text { compound }\end{array}$ & Compound & $\begin{array}{l}\text { Quantity } \\
{[\mathrm{mg} / \mathrm{ml}]}\end{array}$ & Activity on the WCR larvae & Literature \\
\hline \multirow[t]{3}{*}{ Fatty acids } & $\begin{array}{l}\text { Linoleic acid (cis, cis-9,12-octadeca- } \\
\text { dienoic acid, CAS 60-33-3) }\end{array}$ & 4.8 & $\begin{array}{l}\text { This acid acts as a feeding } \\
\text { stimulant and attractant }\end{array}$ & $\begin{array}{l}\text { (Hibbard et al. 1994; Bernklau } \\
\text { and Bjostad 2008) }\end{array}$ \\
\hline & $\begin{array}{l}\text { Oleic acid }((9 Z)-O c t a d e c-9-e n o i c ~ a c i d, \\
\text { CAS } 112-80-1)\end{array}$ & 2.4 & $\begin{array}{l}\text { This acid acts as a feeding } \\
\text { stimulant and attractant }\end{array}$ & $\begin{array}{l}\text { (Hibbard et al. 1994; Bernklau } \\
\text { and Bjostad 2008) }\end{array}$ \\
\hline & $\begin{array}{l}\text { Stearic acid (Octadecanoic acid, } \\
\text { CAS 57-11-4) }\end{array}$ & 1.2 & $\begin{array}{l}\text { This acid acts as a feeding } \\
\text { stimulant and attractant }\end{array}$ & $\begin{array}{l}\text { (Hibbard et al. 1994; Bernklau } \\
\text { and Bjostad 2008) }\end{array}$ \\
\hline \multirow[t]{3}{*}{ Sugars } & Glucose (CAS 50-99-7) & 30 & $\begin{array}{l}\text { This sugar acts as a feeding } \\
\text { stimulant and attractant }\end{array}$ & (Bernklau and Bjostad 2008) \\
\hline & Fructose (CAS 57-48-7) & 4 & $\begin{array}{l}\text { This sugar acts as a feeding } \\
\text { stimulant and attractant }\end{array}$ & (Bernklau and Bjostad 2008) \\
\hline & Sucrose (CAS 57-50-1) & 4 & $\begin{array}{l}\text { This sugar acts as a feeding } \\
\text { stimulant and attractant }\end{array}$ & (Bernklau and Bjostad 2008) \\
\hline \multirow[t]{2}{*}{ Others } & $\mathrm{CO} 2$ & $\begin{array}{l}\text { As much as } \\
\text { possible }\end{array}$ & $\begin{array}{l}\text { Triggers foraging behavior in } \\
\text { soil dwelling insects }\end{array}$ & (Strnad et al. 1986) \\
\hline & MBOA & 0.001 & $\begin{array}{l}\text { This compounds acts as } \\
\text { attractant }\end{array}$ & (Bjostad and Hibbard 1992) \\
\hline
\end{tabular}


depending on the particular experiment. As a negative control a first experiment was done with soil only in racks (1) and (5). A positive control was obtained by including a maize plant (10 days old, var. Delprim) in rack (1). A third set of three experiments was conducted with soil only in rack (1) and capsules with three different coatings in rack (5). The final experiments tested the attractiveness of a maize plant (10 days old, var. Delprim) in rack (1) versus capsules with three different coatings in rack (5). The central rack (3), from which the larvae were released, was first filled with a $3 \mathrm{~cm}$ layer of soil on top of which 30 second instar WCR larvae were carefully deposited. The rack was then filled to the top with more soil. For experiments with capsules, 10 alginate capsules were added to the rack (5) following the same procedure.

Similar as in the Petri-dishes, three alginate formulations were tested, (i) a formulation made of 95:5 demineralized water:maize root juice (obtained as described above), (ii) a formulation containing alginate and a synthetic blend of linoleic acid, oleic acid, stearic acid, glucose, fructose, sucrose and MBOA (for concentrations and references see Table 2) and (iii) a formulation with alginate only as a control. All the capsules were produced with a 10 min polymerization period, but no EPN were added. Once the five racks were arranged at equidistance in the box, the remaining space in between the racks was also completely filled with soil. The box was stored at room temperature $\left(25^{\circ} \mathrm{C}\right)$ before sampling. After $24 \mathrm{~h}$, each rack was dug out of the box and the number of WCR larvae present in this defined volume of soil was recorded. Each experiment was repeated five times.

Field test of the efficiency of encapsulated nematodes

To test the efficacy of encapsulated EPN in controlling WCR under realistic field conditions, a maize field was planted in Missouri (Bradford Research and Extension Center, Columbia, MO, USA) on May $10^{\text {th }}$, 2011. Each plot had 3 rows of 8 plants with $19 \mathrm{~cm}$ plant spacing and $76 \mathrm{~cm}$ row spacing. For the experiment, a total of 72 plots were selected. Each plot was bordered by 1 row on each side, plus 2 plants on each end, which served as buffers between plots. Twelve plots, randomly selected, were assigned to one of the six following treatments; capsules without EPN without chemical coating, capsules without EPN with chemical coating, capsules with EPN without chemical coating, capsules with EPN with chemical coating, sprayed water without EPN and sprayed water with EPN.

On June $1^{\text {st }}$, 2011, WCR eggs were suspended in $0.15 \%$ Agar and around 680 eggs were inoculated every $30 \mathrm{~cm}, 10 \mathrm{~cm}$ deep over the entire experimental field. Three weeks later, on June $22^{\text {nd }}, 2011$, alginate capsules without nematodes (control) were formed following the methodology previously described with the only modification that the volume of the inner liquid core was about $1 \mathrm{ml}$ instead of $0.5 \mathrm{ml}$. In total, 700 capsules were produced, 350 coated with the synthetic blend feeding stimulants and attractants (Table 2) and 350 with alginate only. Within the dedicated plots, each plant received one of the control capsule, manually deposited $10 \mathrm{~cm}$ deep, $3 \mathrm{~cm}$ from the plant stem. On June $23^{\text {rd }}, 2011$, the same numbers of alginate capsules with nematodes (H. bacteriophora, Becker Underwood, Ames, IA, USA, 2'700 infective juveniles per capsule resulting in 300'000 infective juveniles $/ \mathrm{m}^{2}$ ) were formed following the same methodology. Again, 350 were coated with the synthetic blend feeding stimulants and attractants (Table 2) and 350 with alginate only and within the dedicated plots, each plant received one of the EPN containing capsules, manually deposited $10 \mathrm{~cm}$ deep, $3 \mathrm{~cm}$ from the plant stem. On the morning of the June $24^{\text {th }}, 2011$, the remaining 24 plots were sprayed with $7 \mathrm{~L}$ of water each from $30 \mathrm{~cm}$ height with a watering can. In half of the plots, EPN (H. bacteriophora, Becker Underwood, Ames, IA, USA, 300'000 infective juveniles $/ \mathrm{m}^{2}$ ) were poured into the water prior to spraying.

On July $8^{\text {th }}, 2011$, the plants in each plot were dug out to assess root damage. Plants were immediately removed and the root systems were washed and the same day the larval feeding damage was assessed according to the 0-3 root scale (Oleson et al. 2005).

Statistical analyses

\section{EPN breakthrough from the capsules}

The capacity of EPN to escape from the capsule when stored at room temperature or in a fridge was tested with a Two-Way RM ANOVA using the capsule thickness (polymerization period) and escape time as factors to evaluate their respective effect on the number of nematodes exiting the capsules. Statistical differences within groups were calculated using a Tukey post-hoc test. The difference between the total number of EPN 
counted out of the capsule when stored either at $25^{\circ} \mathrm{C}$ or $10^{\circ} \mathrm{C}$ was tested with a $t$-test.

\section{Ability of the encapsulated nematodes to kill insect host}

Statistical differences in EPN speediness at escaping from the capsule and killing their insect host were evaluated using an ANOVA on Ranks. Statistical differences between shell thicknesses were calculated using a Tukey post-hoc test.

\section{Attraction of WCR larvae}

WCR larvae choices among the different coating of the capsule in the Petri-dishes were examined with a $\log$ linear model. The entity computing a repetition in the statistical analysis corresponds to the response of a group of WCR larvae released, which was shown to follow a multinomial distribution (Ricard and Davison 2007). Because the data did not conform to simple variance assumptions implied in using the multinomial distribution, we used quasi-likelihood functions to compensate for the overdispersion of WCR larvae within the Petri-dishes (Turlings et al. 2004).

The behavior of WCR larvae in the boxes was tested with a Two-Way ANOVA using the position of the racks and the treatments of the shell as factor to differentiate the number of WCR larvae sampled. Statistical differences within groups were calculated using a Tukey post-hoc test.

\section{Field test of the efficiency of encapsulated nematodes}

The effect of the different treatments applied to the plants was analyzed with a One-Way ANOVA. Statistical differences within groups were calculated using a LSD post-hoc test.

\section{Results}

EPN breakthrough from the capsules

The capacity of EPN to escape from the capsules when stored at room temperature was significantly different for different periods of storage and there was a significant interaction between the period of storage and the thickness of the shell, but the thickness of the shell did not significantly influence the eventual number of EPN breaking through the capsules over the total observation time (Two-Way RM ANOVA; Fthickness $_{4,149}=0.691, P=0.609 ;$ Fperiod $_{5,149}=21.125$, $P<0.001$; Fthickness $\times$ period $_{20,149}=5.322, P<0.001$ ). As illustrated in Fig. 1a, at room temperature, the time needed for EPN to escape from the capsules with different thickness varied over a range of 1 to more than 3 days.

Also, when stored at $10^{\circ} \mathrm{C}$ (Fig. 1b), EPN movement through the capsule shell was significantly influenced by the thickness of the shell, as well as by the period of storage. The interaction between thickness and period did significantly impact on the EPN break through the shell (Two-Way RM ANOVA; Fthickness $_{4,149}=5.044, P=0.008$; Fperiod $_{5,149}=$ 13.526, $P<0.001 ;$ Fthickness $\times$ period $20,149=1.614$, $P=0.0 .062$ ). In these colder storage conditions, EPN were less motile and only few escaped. Therefore, within a category of shell thickness there were only differences in the number of escaped nematodes between day 1 and the other days within the three thickest shell types. The thickness of the shell notably influenced the movement of EPN through the shell since escape decreased significantly with increasing shell thickness (Fig. 1b). The total number of nematode coming out of the capsules stored at room temperature was twofold higher as compared to the total of EPN exiting the capsules stored at $10^{\circ} \mathrm{C}$ (average total number of EPN out of the capsules after 6 days at room temp: $95.9 \pm 6.3$, at $10^{\circ} \mathrm{C}: 44.04 \pm 11.2$; $t$-test; $t=5.563$, $P<0.001)$.

Ability of the encapsulated nematodes to kill insect hosts

The thickness of the shell had a significant impact on the ability of the encapsulated EPN to kill larvae of $G$. mellonella (ANOVA on Ranks; $H=13.843, P=0.008$ ). Indeed, EPN needed twice as much time to infect the insect host when they were encapsulated with 15 or $20 \mathrm{~min}$ of shell polymerization than with 5 or $7 \mathrm{~min}$ of shell polymerization (Fig. 2). A shift occurred when the shell was polymerized for $10 \mathrm{~min}$ (Fig. 2). None of the G. mellonella larvae died in the control tests. 


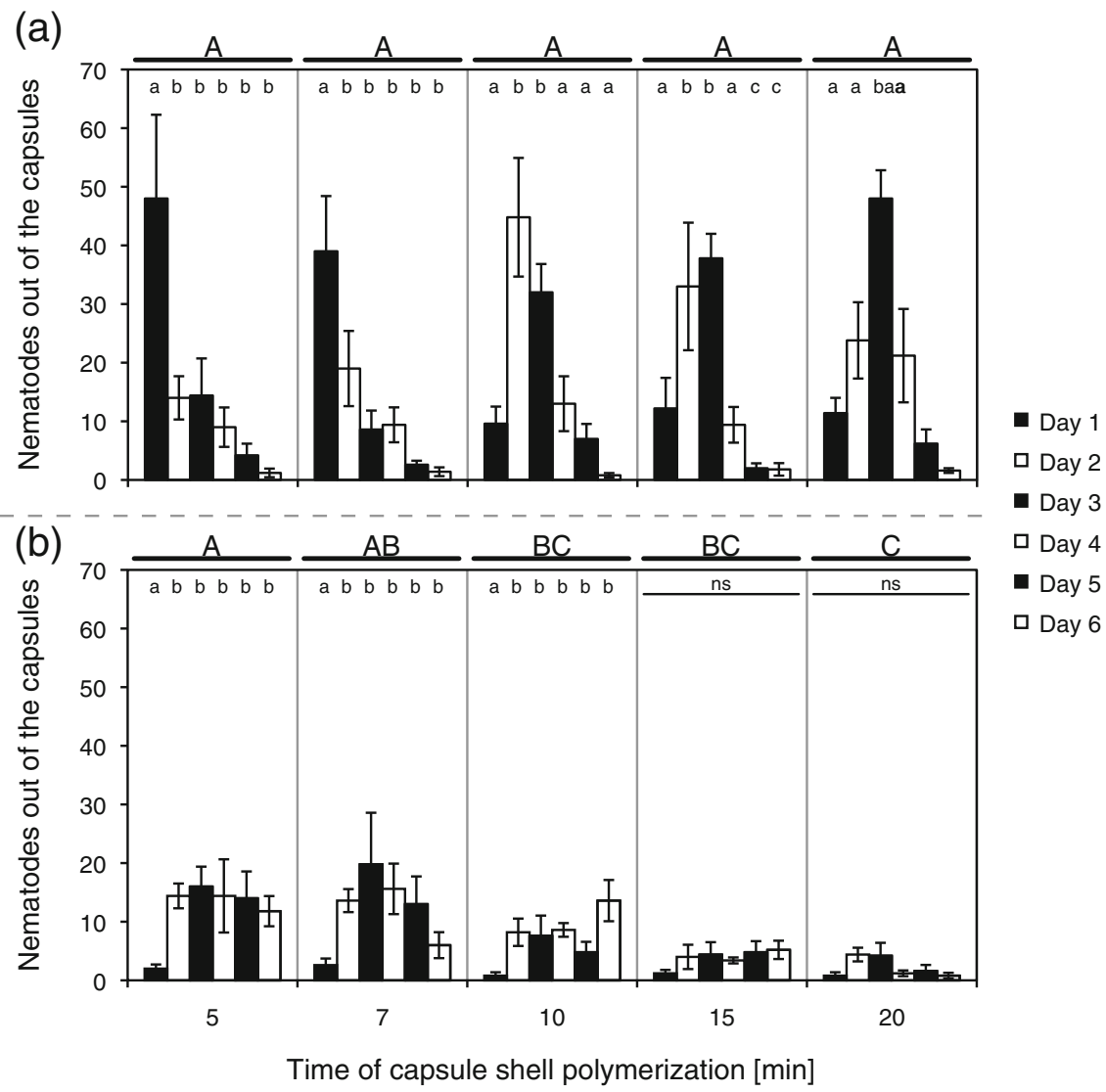

Fig. $1 H$. bacteriophora is able to escape from the capsules. a When stored at room temperature, the EPN were faster in getting out of the capsule inversely proportional to the polymerization period. However, the shell thickness had no influence on the total number of nematodes that eventually were able to get out of the capsule. $\mathbf{b}$ If stored at $10^{\circ} \mathrm{C}$, the nematodes were less likely to get out of the capsules independent of the shell

\section{Attraction of WCR larvae}

In Petri-dishes, the treatments of the capsule shell had a significant impact on the WCR larval behavior (ANOVA; $F_{2,30}=6.640, P=0.002$ ). When offered the choice between capsules treated with a synthetic blend, with maize root juice or without treatment, the WCR larvae significantly preferred the capsule with synthetic compounds in their shell (Fig. 3). The numbers of WCR larvae attracted towards the capsule treated with root juice or untreated were not significantly different (Fig. 3).

On a larger scale, in the boxes, the total number of the WCR collected differed significantly among rack positions (Two-Way ANOVA; Frack ${ }_{4,199}=2235.820$, $P<0.001)$. In general, the treatments had no significant thickness. In this case, that thickness had a significant influence on the total number of EPN breaking through the capsules. Upper case letters indicate statistical differences between polymerization periods. Lower case letters indicate statistical differences between days of sampling within a specific polymerization period. Bars indicate SEM

impact on the total number of larvae sampled from the boxes (Two-Way ANOVA; Ftreat ${ }_{7,199}=30.635, P=$ 0.372). However, within treatments, the position of the racks significantly influenced the number of WCR larvae that were recovered (Two-Way ANOVA; Frack $x$ treat $\left._{28,199}=4050.395, P<0.001\right)$. In the controls, when no choices were offered, the WCR larvae mainly stayed in the central rack (number 3), where they had been released (Fig. 4a). But when offered a choice between a maize plant and nothing, the larvae preferably moved toward the plant (Fig. 4a). When offered only capsules with synthetic stimulants the larvae were significantly more attracted towards the capsules (Fig. 4b), but capsules coated with root extracts were not attractive to the larvae (Fig. 4b), nor were the control capsules without stimulants or extract (Fig. 4b). When offered a choice 


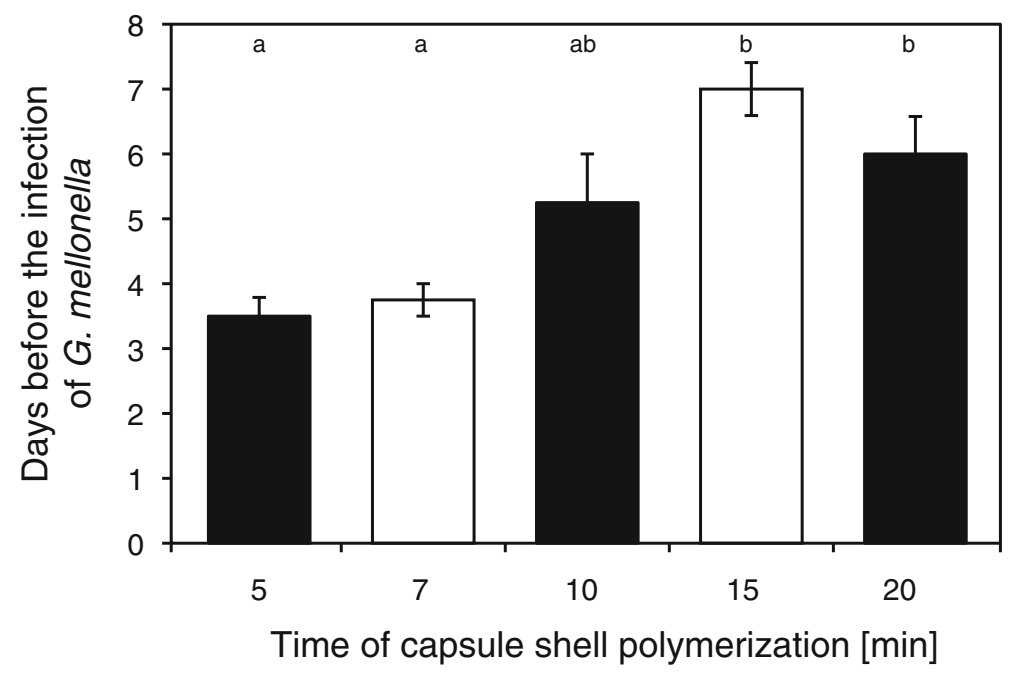

Fig. $2 H$. bacteriophora nematodes that breakthrough the capsule shell, are still infectious and able to kill $G$. mellonella insects. Even though the polymerization period significantly affected the time needed for the EPN to infect the insects, none

between capsules coating with synthetic stimulants and a plant, the larvae showed no preference, but tended to move towards both treatments (Fig. 4c). The larvae moved more toward the plant when they were offered a choice between a plant and capsules coated with root extract or uncoated capsules (Fig. 4c). of the shell thicknesses kept EPN from successfully kill their host. Lower cases indicate statistical differences in infection time among polymerization periods and error bars indicate SEM

Field test of the efficiency of encapsulated nematodes

Statistical differences were measured among the six different treatments in the field trial (One-Way ANOVA, $F_{7,88}=2.7533, P=0.01$, Fig. 5). When EPN were applied, plants received significantly less damage, independent of

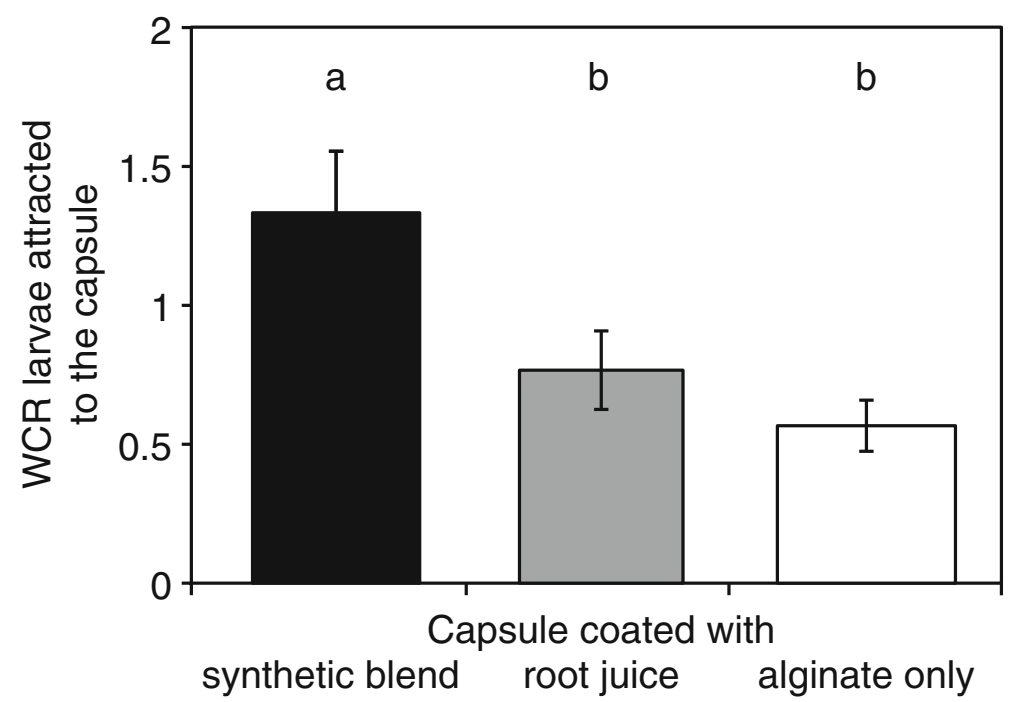

Fig. 3 In Petri dishes, the coating of the capsules significantly lures WCR larvae towards the capsules. Significantly more WCR larvae were found near the capsules coated with the synthetic blend compared to the coating with root juice. Approximately twice the number of WCR larvae were found near capsules coated with the synthetic blend alginate than near the uncoated control capsules. No difference in attraction was found between root juice and alginate coating. Lower case letters indicate statistical differences and error bars indicate SEM 
Fig. 4 Effects of the capsule coating on attraction of WCR larvae in a semi-natural environment. The surface of the circles represents the mean number of WCR larvae recovered in the potted soil after $24 \mathrm{~h}$ of exposure to the different treatments. The white outer part of each disc represents the SEM of the particular mean. Coatings of the capsules are symbolized along a grey scale defined in the figure. Drawings indicate the treatments applied to the specific rack in the assay box. Upper case letters indicate statistical differences between rack 1 and rack 5. Lower case letters indicate statistical differences within treatments. a When no plant or no capsules were offered, the WCR larvae mainly stayed in the central rack. In contrast, the larvae moved towards the plant when they were offered a maize plant (var. Delprim) in rack 1 . b When offered capsules coated with the synthetic blend of attractants, the larvae were significantly attracted to rack 5 , where the capsules had been placed. The capsules coated with either root extracts or alginate only had no significant influence on larval attraction. c Interestingly, when offered the choice between a maize plant and capsules, the larvae did not show a preference for one of the sides. Again, capsules with root extracts and uncoated capsules were not attractive to the larvae, as they were moved significantly more toward the plant

the application technique (Fig. 5), but in plots where nematodes were applied in capsules, roots received significantly less damage than in plots where the nematodes were sprayed in water (Fig. 5). However, coating the capsule shell with feeding stimulants and attractants did not improve root protection under these conditions (Fig. 5).

\section{Discussion}

All tests that were conducted to assess the potential of releasing EPN in an alginate capsule formulation showed encouraging results. In addition to surviving the encapsulation process, the nematodes were able to break through the shell and to infect insect hosts (Figs. $1 \& 2$ ). This ability of EPN to exit the capsules has to be kept in mind if the capsules are stored for longer periods before application in the field. However, a combination of the right shell thickness and appropriate storing could solve this. Indeed, reducing their motility with cold temperature made nematodes stay longer in the capsules (Fig. 1). The shell thickness also influenced the nematode exit of the capsules, as at room temperature, the time needed for EPN to kill insect hosts (G. mellonella larvae) was positively correlated with shell thickness (Fig. 2). Adding synthetic attractants and feeding stimulants to the shell of the capsules incited

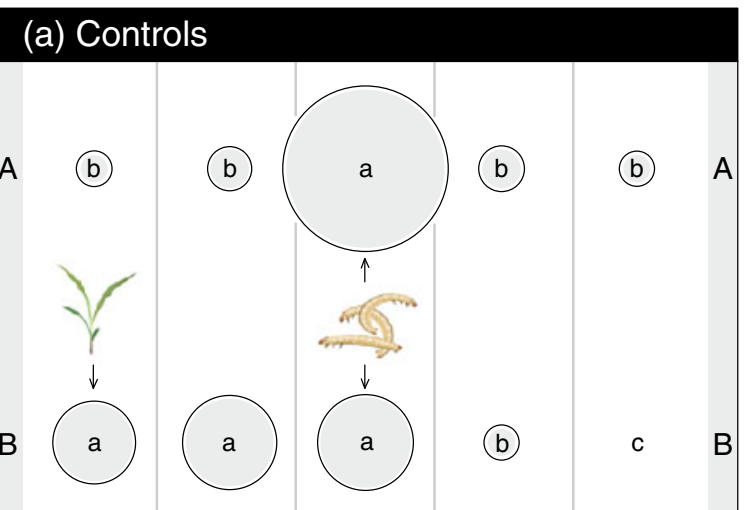

(b) Capsule only

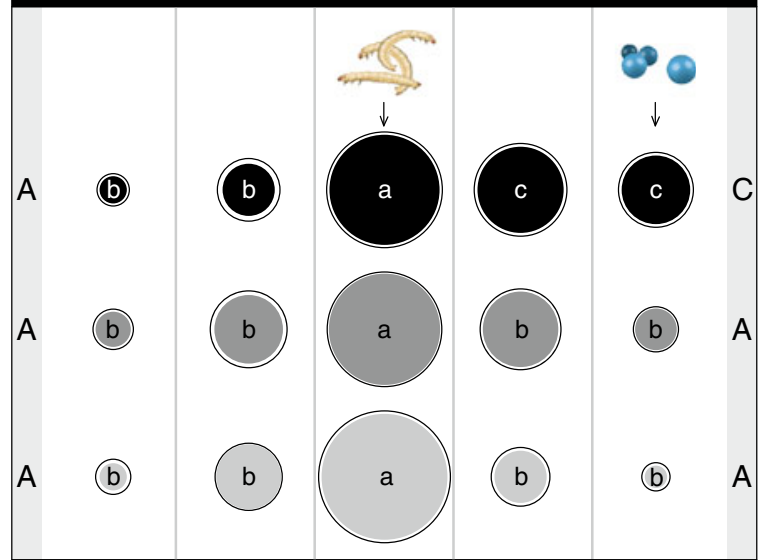

(c) Capsule vs maize plant(var. Delprim)

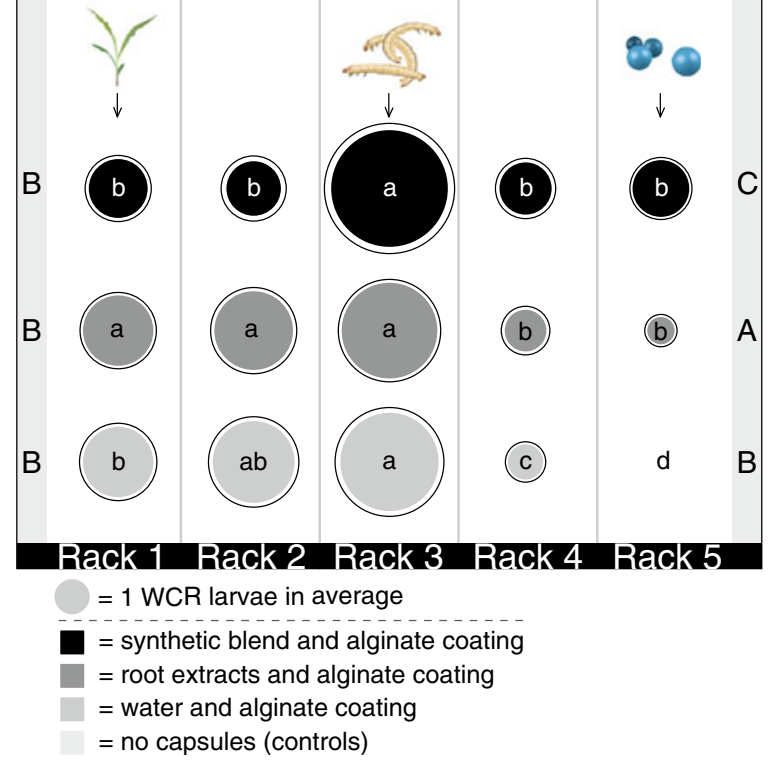

the larvae to move towards the capsules. In both Petri dish and box experiments, WCR larvae were more attracted toward capsules treated with the synthetic blend 


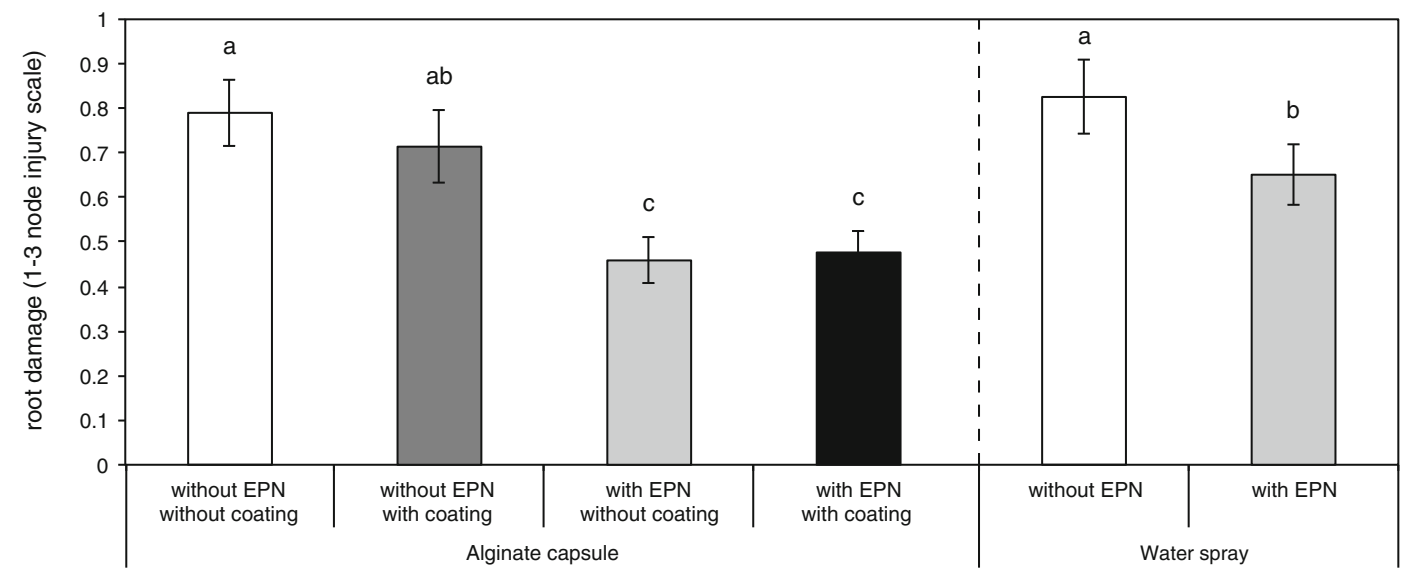

Fig. 5 In field assays, EPN application always resulted in significant control of WCR larvae. Application of capsules containing EPN provided significantly better protection against root damage than EPN sprayed in water. Coating the capsule

as compared to capsules with root extracts or untreated capsules (Figs. 3 \& 4). Interestingly, the capsules coated with the synthetic blend were as attractive as the roots of a maize plant under laboratory conditions (Fig. 4). WCR control in the field was significantly better when EPN were applied in capsules than when they were sprayed over the field. However, under field condition, the coating of the capsule did not enhance WCR control (Fig. 5). Overall, the results of this study underline the great potential of this application technique of EPN against WCR.

Field studies that tested EPN against larvae of several Diabrotica pests have already shown promising results, both in the USA and in Europe (Creighton and Fassuliotis 1985; Ellsbury et al. 1996; Hiltpold et al. 2010c; Jackson 1996; Kaya et al. 1989; Poinar et al. 1983; Rasmann et al. 2005). Yet, control of the pests was inconsistent; while some studies demonstrate a high level of control, others showed a weak efficacy of the tested nematodes (Georgis and Gaugler 1991; Jackson and Brooks 1995; Riga et al. 2001; Wright et al. 1993). Failures have often been explained by the unfavorable abiotic conditions of the soils, such as moisture, they were applied to (Gouge and Shapiro-Ilan 2003). Other authors proposed the lack of alternative hosts as a possible reason for these failures (Brust 1991; Susurluk 2005) or an inadequate choice of the maize variety (Hiltpold et al. 2010c). However, Smits (1996) and more recently Cabanillas et al. (2005) suggested that the application methods have significant consequences for EPN efficacy in controlling pests. In recent studies, Toepfer et al. (2010a, b) compared six different with chemical stimulants did not improve EPN effectiveness. Lower cases letters indicate statistical differences in root damage and error bars in bars indicate SEM

application techniques (three ways of spraying into soil and three ways of spraying onto soil) of $H$. bacteriophora to control WCR in Southern Hungary. At the plant scale as well as at the field scale, all techniques resulted in fairly good control of pest larvae. The overall conclusion is that the release technique itself is of minor importance as long as the nematodes can quickly enter soil and encounter an adequately moist and dark environment. To achieve such conditions, most of the techniques tested by Toepfer et al. $(2010 \mathrm{a}, \mathrm{b})$ required the use of large amounts of water in order to moisten the soil surface sufficiently to allow nematode to penetrate into the soil matrix.

To overcome the costs incurred by the high water consumption and in some cases the high frequency by which the machinery needs to pass through a maize field, the development of a cost-effective method of EPN delivery with capsules has been proposed by Toepfer et al. (2010b). Kaya and Nelsen (1985) already tested the approach by encapsulating two EPN species in alginate capsules. They showed that encapsulated nematodes were able to infect and kill Spodoptera exigua when moisture levels were appropriate (Kaya and Nelsen 1985). Alginate was also successfully used as a surfactant in EPN foliar application (Schroer et al. 2005; Navon et al. 2002; Navon et al. 1998). Pellets of alginate containing the fungus Hirsutella rhossiliensis have been proposed for the control of plant-parasitic nematodes (Lackey et al. 1993). With realistic field assays, the present study shows the clear potential of the approach for WCR control. 
From the literature and from our own studies we identify the following key factors determining nematodes efficacy in controlling a soil pest: (i) the specificity of the nematode strain to the targeted pest (Gouge and ShapiroIlan 2003; Jackson and Brooks 1995), (ii) their foraging strategy (Gaugler et al. 1997), (iii) their ability to move and persist in the soil matrix (Georgis and Gaugler 1991) and finally (iv) the soil surface moisture at time of application (Gaugler 2002). Most of these factors are addressed by the potent application technique proposed in the present study. The nematode tested, $H$. bacteriophora, has been shown to be effective against most larval instars of WCR (Kurzt et al. 2009) and exhibits an active host finding behavior (Grewal et al. 1994; Lewis 2002). In the case of maize, the success of this behavior can be improved by selecting for $H$. bacteriophora strains with enhanced responsiveness to root produced attractants (Hiltpold et al. 2010a, b). Moreover, the persistence of this species in soil is long enough that it can control WCR when applied early in the season (Kurtz et al. 2007). Until now, the surface soil moisture problem was the hardest issue to overcome. The capsule technique reported here offers promising perspective. Indeed, having capsules "planted" in soil together with the seeds would save tremendous amounts of water and positions the nematodes in the exact location where they are needed. This was confirmed in the field where, in addition to a better control of WCR in the plots with capsules containing EPN (Fig. 5), the application of encapsulated EPN consumed in total $\sim 0.5 \mathrm{~L}$ of water, whereas $\sim 2,000 \mathrm{~L}$ of water were sprayed in the other plots sprayed with EPN. Moreover, the attraction of the larvae toward the capsules may offer several additional advantages. Obviously, it would make it easier for the EPN to find the pest larvae but, also, since with the right formulation, the capsules are as attractive as maize roots, the capsules could also act as a host-location disruptor in the field and thereby further negatively affect WCR larvae. Such beneficial effects of the coating were expected from the laboratory results (Figs. $3 \& 4$ ), nonetheless, the chemical coating of the capsule shell did not enhance the control of the pest in the field (Fig. 5). Several explanations are proposed: (i) compared to the laboratory experiment, the number of capsules applied in the field was very low, hence the concentration of chemicals might not have been sufficient to lure WCR larvae towards them, (ii) the infection with WCR eggs was done close to the plants, hence hatching larvae did not have to forage much before finding host plant and (iii) at the time the capsules were applied, most WCR larvae probably already had hatched and established themselves on the maize roots, hence reducing their movement in soil.

Further improvements of the capsule are still needed before field large-scale application. Indeed, the present formulation results in a gummy capsule that would not resist pressures in the machinery used by growers. We are currently working on alternate formulation that would provide hard-shelled capsules and may allow large-scale applications with available machinery. Also, the attractant formulation can be improved as additional attractants and feeding stimulants are being discovered (Robert et al. 2012a,b). The complementary effects of employing attractive capsule on the control of WCR have to be tested further in the field with improved combinations and concentrations of chemicals in the capsule and appropriate timing of application. Yet, the results from our laboratory experiments show good prospects for realistic application of encapsulated EPN in the control of WCR and other soil pests.

Acknowledgments We thank all the members of the FARCE lab at the University of Neuchâtel, in particular Gregory Roeder and Christophe Praz for their support and stimulating discussions and Matthias Held for his valuable advice in statistical analyses. We would like to thank the U.S. Department of Agriculture field crew in Columbia, MO, USA, for their help in the field. H. bacteriopohora were kindly provided by LANDI-Reba AG (R. Burger, Basel, Switzerland) and Becker Underwood (J. Graesh, Ames, IA, USA). The work was supported by a Swiss economic stimulus grant awarded to the National Center of Competence in Research (NCCR) Plant Survival.

\section{References}

Ansari MA, Hussain M, Moens M (2009) Formulation and application of entomopathogenic nematode-infected cadavers for control of Hoplia philanthus in turfgrass. Pest Manag Sci 65:367-374

Apple JW, Patel KK (1963) Sequence of attack by northern corn rootworms on the crown roots of maize. Proc N Central Branch, Entomol Soc Am 18:80-81

Batalla-Carrera L, Morton A, Garcia-del-Pino F (2010) Efficacy of entomopathogenic nematodes against the tomato leafminer Tuta absoluta in laboratory and greenhouse conditions. Biocontrol 55:523-530

Bernklau EJ, Bjostad LB (2008) Identification of feeding stimulants in corn roots for western corn rootworm (Coleoptera: Chrysomelidae) larvae. J Econ Entomol 101:341-351

Bernklau EJ, Fromm EA, Bjostad LB (2004) Disruption of host location of western corn rootworm larvae (Coleoptera: 
Chrysomelidae) with carbon dioxide. J Econ Entomol 97:330-339

Bjostad LB, Hibbard BE (1992) 6-Methoxy-2-benzoxazolinone - a semiochemical for host location by western corn rootworm larvae. J Chem Ecol 18:931-944

Brust GE (1991) Augmentation of an endemic entomogenous nematode by agroecosystem manipulation for control of a soil pest. Agric Ecosyst Environ 36:175-184

Burnell AM, Stock SP (2000) Heterorhabditis, Steinernema and their bacterial symbionts-lethal pathogens of insects. Nematology 2:31-42

Cabanillas HE, Wright RJ, Vyas RV (2005) Cereal, fibre, oilseed and medicinal crop applications. In: Grewal PS, Ehlers RU, Shapiro-Ilan DI (eds) Nematodes as biocontrol agents. CABI Publishing, Wallingford, pp 265-280

Chiang HC, French LK, Rasmussen DE (1980) Quantitative relationship between western corn-rootworm population and corn yield. J Econ Entomol 73:665-666

Creighton CS, Fassuliotis G (1985) Heterorhabditis sp (Nematode, Heterorhabditidae) - a nematode parasite isolated from the banded cucumber beetle Diabrotica balteata. J Nematol 17:150-153

Degenhardt J, Hiltpold I, Köllner TG, Frey M, Gierl A, Gershenzon J, Hibbard BE, Ellersieck MR, Turlings TCJ (2009) Restoring a maize root signal that attracts insect-killing nematodes to control a major pest. Proc Natl Acad Sci USA 106:1321313218

Ellsbury MM, Jackson JJ, Woodson WD, Beck DL, Stange KA (1996) Efficacy, application distribution, and concentration by stemflow of Steinernema carpocapsae (Rhabditia: Steinernematide) suspensions applied with a lateral-move irrigation system for corn rootworm (Coleoptera: Chrysomelidae) control in maize. J Econ Entomol 85:2425-2432

Forst S, Clarke D (2002) Bacteria-nematode symbiosis. In: Gaugler R (ed) Entomopathogenic nematology. CABI International, pp 57-77

Gaugler R (2002) Entomopathogenic nematology. CABI publishing, Wallingford

Gaugler R, Boush GM (1978) Effects of ultraviolet-radiation and sunlight on entomogenous nematode, Neoaplectana carpocapsae. J Invertebr Pathol 32:291-296

Gaugler R, Lewis E, Stuart RJ (1997) Ecology in the service of biological control: the case of entomopathogenic nematodes. Oecologia 109:483-489

Georgis R, Gaugler R (1991) Predictability in biological-control using entomopathogenic nematodes. J Econ Entomol 84:713-720

Girolami V, Mazzon L, Squartini A, Mori N, Marzaro M, Di Bernardo A, Greatti M, Giorio C, Tapparo A (2009) Translocation of neonicotinoid insecticides from coated seeds to seedling guttation drops: a novel way of intoxication for bees. J Econ Entomol 102:1808-1815

Godfrey LD, Meinke LJ, Wright RJ (1993) Effects of larval injury by western corn-rootworm (Coleoptera, Chrisomelidae) on gas-exchange parameters of field corn. J Econ Entomol $86: 1546-1556$

Gouge DH, Shapiro-Ilan DI (2003) Case studies in cotton and citrus: use of entomopathogenic nematodes. Indian J Nematol 33:91-102

Gray ME, Steffey KL (1998) Corn rootworm (Coleoptera: Chrysomelidae) larval injury and root compensation of 12 maize hybrids: an assessment of the economic injury index. J Econ Entomol 91:723-740

Gray ME, Sappington TW, Miller NJ, Moeser J, Bohn MO (2009) Adaptation and invasiveness of western corn rootworm: Intensifying research of a worsening pest. Annu Rev Entomol 54:303-321

Grewal PS, Lewis EE, Gaugler R, Campbell JF (1994) Host finding behavior as a predictor of foraging strategy in entomopathogenic nematodes. Parasitology 108:207215

Grewal PS, Ehlers RU, Shapiro DI (2005) Nematodes as biocontrol agents. CABI Publishing, Wallingford

Hibbard BE, Bernklau EJ, Bjostad LB (1994) Long-chain free fatty-acids - semiochemicals for host location by western corn rooworm larvae. J Chem Ecol 20:3335-3344

Hiltpold I, Turlings TCJ (2008) Belowground chemical signalling in maize: when simplicity rhymes with efficiency. $J$ Chem Ecol 34(5):628-635

Hiltpold I, Baroni M, Toepfer S, Kuhlmann U, Turlings TCJ (2010a) Selection of entomopathogenic nematodes for enhanced responsiveness to a volatile root signal helps to control a major root pest. J Exp Biol 213 (14):2417-2423

Hiltpold I, Baroni M, Toepfer S, Kuhlmann U, Turlings TCJ (2010b) Selective breeding of entomopathogenic nematodes for enhanced attraction to a root signal did not reduce their establishment or persistence after field release. Plant Signal Behav 5:1450-1452

Hiltpold I, Toepfer S, Kuhlmann U, Turlings TCJ (2010c) How maize root volatiles influence the efficacy of entomopathogenic nematodes against the western corn rootworm? Chemoecology 20:155-162

Hou X, Meinke LJ, Arkebauer TJ (1997) Soil moisture and larval western corn rootworm injury: Influence on gas exchange parameters in corn. Agron J 89:709-717

Jackson JJ (1996) Field performance of entomopathogenic nematodes for suppression of western corn rootworm (Coleoptera: Chrysomelidae). J Econ Entomol 89:366-372

Jackson JJ, Brooks MA (1995) Parasitism of western corn rootworm larvae and pupae by Steinernema carpocapsae. J Nematol 27:15-20

Johnson SN, Gregory PJ (2006) Chemically-mediated host-plant location and selection by root-feeding insects. Physiol Entomol 31:1-13

Kaya HK, Nelsen CE (1985) Encapsulation of steinernematid and heterorhabditid nematodes with calcium alginate: a new approach for insect control and other applications. Environ Entomol 14:572-574

Kaya HK, Gaugler R (1993) Entomopathogenic nematodes. Annu Rev Entomol 38:181-206

Kaya HK, Leong KLH, Burlando TM, Smith K, Yoshimura MA (1989) Entomogenous nematodes for biological control of the western spotted cucumber beetle, Diabrotica undecimpunctata. J Nematol 21:568-569

Köllner T, Held M, Lenk C, Hiltpold I, Turlings TCJ, Gershenzon J, Degenhardt J (2008) A maize (E)-BETA-caryophyllene synthase implicated in indirect defense responses against herbivores is not expressed in most American maize varieties. Plant Cell 20:482-494

Kuhlmann U, van der Brugt WACM (1998) Possibilities for biological control of the western corn rootworm, Diabrotica 
virgifera virgifera LeConte, in Central Europe. Biocontrol $19: 59 \mathrm{~N}-68 \mathrm{~N}$

Kurtz B, Toepfer S, Ehlers RU, Kuhlmann U (2007) Assessment of establishment and persistence of entomopathogenic nematodes for biological control of western corn rootworm. J Appl Entomol 131:420-425

Kurzt B, Hiltpold I, Turlings TCJ, Kuhlmann U, Toepfer S (2009) Comparative susceptibility of larval instars and pupae of the western corn rootworm to infection by three entomopathogenic nematodes. Biocontrol 54:255-262

Lackey BA, Muldoon AE, Jaffee BA (1993) Alginate pellet formulation of Hirsutella rhossiliensis for biological control of plant-parasitic nematodes. Biol Contr 3:155-160

Levine E, Spencer JL, Isard SA, Onstad DW, Gray ME (2002) Adaptation of the western corn rootworm, Diabrotica vigifera virgifera LeConte (Coleoptera: Chrysomelidae), to crop rotation: evolution of a new strain in response to a cultural management practice. Am Entomol 48:94107

Lewis EE (2002) Behavioural ecology. In: Gaugler R (ed) Entomopathogenic nematology. CABI International, pp 205-223

Marzaro M, Vivan L, Targa A, Mazzon L, Mori N, Greatti M, Toffolo EP, Di Bernardo A, Giorio C, Marton D, Tapparo A, Girolami V (2011) Lethal aerial powdering of honey bees with neonicotinoids from fragments of maize seed coat. Bull Insectol 64:119-126

Mbata GN, Shapiro-Ilan DI (2010) Compatibility of Heterorhabditis indica (Rhabditida: Heterorhabditidae) and Habrobracon hebetor (Hymenoptera: Braconidae) for biological control of Plodia interpunctella (Lepidoptera: Pyralidae). Biol Contr 54:75-82

Mitchell P (2011) Costs and benefits of controlling pest Diabrotica in maize in the United States. Paper presented at the 24th IWG Conference, Freiburg, Germany, pp 24-26 Oct. 2011

Navon A, Keren S, Salame L, Glazer I (1998) An edible-toinsects calcium alginate gel as a carrier for entomopathogenic nematodes. Biocontrol Sci Technol 8:429-437

Navon A, Nagalakshmi VK, Levski S, Salame L, Glazer I (2002) Effectiveness of entomopathogenic nematodes in an alginate gel formulation against lepidopterous pests. Biocontrol Sci Technol 12:737-746

Oleson JD, Park YL, Nowatzki TM, Tollefson JJ (2005) Nodeinjury scale to evaluate root injury by corn rootworms (Coleoptera: Chrysomelidae). J Econ Entomol 98:1-8

Poinar GO, Evans JS, Schuster E (1983) Field-tests of the entomogenous nematode, Neoaplectana carpocapsae, for control of corn-rootworm larvae (Diabrotica sp, Coleoptera). Protect Ecol 5:337-342

Rasmann S, Köllner TG, Degenhardt J, Hiltpold I, Toepfer S, Kuhlmann U, Gershenzon J, Turlings TCJ (2005) Recruitment of entomopathogenic nematodes by insect-damaged maize roots. Nature 434(7034):732-737

Ricard I, Davison AC (2007) Statistical inference for olfactometer data. J R Stat Soc Ser C Appl Stat 56:479-492

Riedell WE, Gustin RD, Beck DL (1992) Effect of irrigation on root-growth and yield of plants damaged by western cornrootworm larvae. Maydica 37:143-148

Riedell WE, Kim AW (1990) Anatomical characterization of western corn rootworm damage in adventitious roots of maize. J Iowa Acad Sci 97:15-17
Riga E, Whistlecraft J, Potter J (2001) Potential of controlling insect pests of corn using entomopathogenic nematodes. Can J Plant Sci 81:783-787

Robert CAM, Veyrat N, Glauser G, Marti G, Doyen GR, Villard N, Gaillard MDP, Köllner TG, Giron D, Body M, Babst BA, Ferrieri RA, Turlings TCJ, Erb M (2012a) A specialist root herbivore takes advantage of defensive metabolites to locate nutritious tissues. Ecol Lett 15:5564

Robert CAM, Erb M, Duployer M, Zwahlen C, Doyen GR, Turlings TCJ (2012b) Herbivore-induced plant volatiles mediate host selection by a root herbivore. New Phytologist (in press)

Schroer S, Ziermann D, Ehlers RU (2005) Mode of action of a surfactant-polymer formulation to support performance of the entomopathogenic nematode Steinernema carpocapsae for control of diamondback moth larvae (Plutella xylostella). Biocontrol Sci Technol 15:601-613

Shapiro-Ilan DI, Cottrell TE, Mizell RF, Horton DL, Behle RW, Dunlap CA (2010a) Efficacy of Steinernema carpocapsae for control of the lesser peachtree borer, Synanthedon pictipes: improved aboveground suppression with a novel gel application. Biol Contr 54(1):23-28

Shapiro-Ilan DI, Gouge DH, Piggott SJ, Fife JP (2006) Application technology and environmental considerations for use of entomopathogenic nematodes in biological control. Biol Contr 38:124-133

Shapiro-Ilan DI, Lewis EE, Behle RW, McGuire MR (2001) Formulation of entomopathogenic nematode-infected cadavers. J Invertebr Pathol 78:17-23

Shapiro-Ilan DI, Lewis EE, Tedders WL (2003) Superior efficacy observed in entomopathogenic nematodes applied in infected-host cadavers compared with application in aqueous suspension. J Invertebr Pathol 83:270-272

Shapiro-Ilan DI, Morales-Ramos JA, Rojas MG, Tedders WL (2010b) Effects of a novel entomopathogenic nematodeinfected host formulation on cadaver integrity, nematode yield, and suppression of Diaprepes abbreviatus and Aethina tumida. J Invertebr Pathol 103:103-108

Smits PH (1996) Post-application persistence of entomopathogenic nematodes. Biocontrol Sci Technol 6:379-387

Strnad SP, Bergman MK (1986) Movement of first-instar western corn rootworm (Coleoptera: Chrysomelidae) in soil. Environ Entomol 16:975-978

Strnad SP, Bergman MK, Fulton WC (1986) First-instar western corn rootworm (Coleoptera: Chrysomelidae) response to carbon dioxide. Environ Entomol 15:839-842

Susurluk A (2005) Establishment and persistence of the entomopathogenic nematodes Steinernema feltia and Heterorhabditis bacteriophora. Christian Albrechts University, Kiel

Toepfer S, Burger R, Ehlers RU, Peters A, Kuhlmann U (2010a) Controlling western corn rootworm larvae with entomopathogenic nematodes: effect of application techniques on plant-scale efficacy. J Appl Entomol 134:467-480

Toepfer S, Hatala-Zseller I, Ehlers RU, Peters A, Kuhlmann U (2010b) The effect of application techniques on field-scale efficacy: can the use of entomopathogenic nematodes reduce damage by western corn rootwortm larvae? Agr Forest Entomol 12:389-402 
Turlings TCJ, Davison AC, Tamò C (2004) A six-arm olfactometer permitting simultaneous observation of insect attraction and odour trapping. Physiol Entomol 29:45-55

Urias-Lopez M, Meinke LJ, Higley LG, Haile FJ (2000) Influence of western corn rootworm (Coleoptera: Chrysomelidae) larval injury on photosynthetic rate and vegetative growth of different types of maize. Environ Entomol 29:861-867
Wesseler J, Fall EH (2010) Potential damage costs of Diabrotica virgifera virgifera infestation in Europe - the 'no control' scenario. J Appl Entomol 134:385-394

Wright RJ, Witkowski JF, Echtenkamp G, Georgis R (1993) Efficacy and persistence of Steinernema carpocapsae (Rhabditida, Steinernematidae) applied through a centerpivot irrigation system against larval Corn Rootworms (Coleoptera, Chrysomelidae). J Econ Entomol 86:13481354 